\title{
Stroke Prevention With Carotid Compression in Patients Undergoing Transcatheter Aortic Valve Replacement: a Multi-Center Study
}

\author{
Anwar Tandar, MD ${ }^{1 *}$, Kapildeo Luton, $\mathrm{MD}^{2}$, Abdulfattah Saidi, MD ${ }^{1}$, Brian R. Lindman, MD ${ }^{3,6}$, \\ David Bull, MD ${ }^{4}$, Jason Glotzbach, MD ${ }^{4}$, Craig H. Selzman, MD ${ }^{4}$, Amit Patel, MD ${ }^{4}$, \\ Greg Stoddard, PhD ${ }^{5}$, Elizabeth Dranow, PhD ${ }^{1}$, Frederick G.P. Welt, MD ${ }^{1}$ \\ ${ }^{1}$ Division of Cardiovascular Medicine, University of Utah, Salt Lake City, Utah, USA \\ ${ }^{2}$ Division of Cardiovascular Medicine, Banner Health Center, Phoenix, Arizona, USA \\ ${ }^{3}$ Cardiovascular Division, Washington University School of Medicine, St. Louis, Missouri, USA \\ ${ }^{4}$ Division of Cardiothoracic Surgery, University of Utah, Salt Lake City, Utah, USA \\ ${ }^{5}$ Division of Epidemiology, University of Utah, Salt Lake City, Utah, USA \\ ${ }^{6}$ Vanderbilt University Medical Center, Nashville, Tennessee, USA
}

\begin{abstract}
Background: Transcatheter aortic valve replacement (TAVR) has revolutionized the management of severe aortic stenosis. However, TAVR is associated with several complications, including stroke. Carotid compression has been suggested as a simple maneuver to reduce embolic events during various cardiac procedures. Therefore, we examined the association between carotid compression and the incidence of transient ischemic attack (TIA) and stroke in patients undergoing TAVR.

Methods: This is a retrospective multicenter study of patients who underwent TAVR with and without carotid compression. Primary outcomes were stroke or TIA 72 hours after the procedure and between 72 hours and 30-day follow-up. Data analysis was performed using a propensity score technique with inverse probability weighting.

Results: A total of 306 TAVR patients were included in the study. Group I $(n=188)$ and II $(n=118)$ included patients who did not or did undergo carotid compression during TAVR, respectively. The mean age was $82.5 \pm 8.2$ years in Group I and 78.5 \pm 7.6 years in Group II. There was no significant difference in combined stroke or TIA rate 72 hours after the procedure $(1.1 \%$ vs. $1.9 \%, P=$ $0.50)$ or between 72 hours and 30-day follow-up (2.3\%
\end{abstract}

(C) 2018 Journal of Structural Heart Disease Published by Science International Corp. ISSN 2326-4004

Fax +1 2037853346

E-Mail: jshd@scienceinternational.org

http://structuralheartdisease.org/

Accessible online at:

http://structuralheartdisease.org/ vs $1.6 \%, P=0.67$ ).

Conclusions: Carotid compression during the TAVR procedure is not associated with the incidence of composite TIA or stroke after TAVR.

Copyright @ 2018 Science International Corp.

\section{Key Words}

Transcatheter aortic valve replacement - Carotid compression - Stroke - Transient ischemic attack • Severe aortic stenosis

\section{Introduction}

Transcatheter aortic valve replacement (TAVR) has emerged in recent years as an attractive option for treating patients with symptomatic severe aortic stenosis (AS) who are deemed to be at intermediate or high risk for surgical aortic valve replacement (SAVR) [1-3]. As TAVR continues to evolve, it requires improvements in device technology and implantation techniques to minimize the rate of complications such as stroke. Stroke is a devastating complication that has been attributed to procedural factors [4]. The 30-day occurrence of all strokes in the PARTNER $1 \mathrm{~A}$ tri-

* Corresponding Author:

Anwar Tandar, MD

Division of Cardiovascular Medicine

University of Utah

50 North Medical Drive, SOM, Room 4A100, Salt Lake City, UT 84132, USA

Tel. +1 801585 5559; Fax: +1 801581 7735; E-Mail: anwar.tandar@hsc.utah.edu 
al was significantly higher among TAVR patients than among SAVR patients (5.5\% vs. $2.4 \%, P=0.04$ ) in the high-risk cohort [1]. Published 5-year outcomes of the PARTNER 1 trial showed a similar incidence of stroke or transient ischemic attack (TIA) between TAVR and SAVR patients ( $15.9 \%$ vs. $14.7 \%, P=0.3)$ [5]. More recent data show stroke rates of $3.4 \%$ at 30 days in the FRANCE 2 Registry study [6] and procedural/in-hospital stroke rates of $1.8 \%$ in the Transcatheter Valve Treatment Sentinel Pilot Registry [7]. Although the incidence of stroke is declining [8], stroke is strongly associated increased morbidity and mortality $[9,10]$.

The mechanism of stroke after TAVR is presumably embolic in most cases and may differ depending on the timing of stroke and route of access. However, a history of carotid disease may be one predictor of post-procedure strokes [11-13]. Multiple studies utilizing magnetic resonance imaging, trans-cranial Doppler, and filtered and retrieved material have documented nearly universal embolic phenomena during TAVR [14-17]. Hypothetically, stroke prevention can be achieved by minimizing the amount of microemboli showering from the aorta to the brain during TAVR implantation. Anecdotally, several TAVR programs in the United States and Europe perform carotid compression during TAVR to minimize the risk of stroke or TIA [18]. The rationale for this concerns both direct occlusion of the arteries during a period of embolic showering and a change in flow diverting emboli from entering cerebral circulation. Here, we examined the association between carotid compression during TAVR and post-procedural incidence of TIA and stroke.

\section{Materials and Methods}

\section{Patient Population}

The study included patients with symptomatic severe AS who underwent TAVR at the University of Utah Hospital, Washington University Medical Center, or Banner Health Center in Phoenix, Arizona between February 1, 2012 and April 1, 2016. Collected data were part of the Transcatheter Valve Therapy registry. For the purposes of this study, the intervention of interest was whether the patient received carotid compression during the TAVR procedure as documented in the clinical operative report. Patient eligibility for
TAVR was decided at each site by the heart team, which included interventional cardiologists, cardiothoracic surgeons, imaging cardiologists, and cardiac anesthesiologists. Members of the heart teams at all three centers were similarly trained and qualified to treat TAVR patients. Enrolled patients were divided into two groups: Group I included patients who underwent TAVR without carotid compression, and Group II included patients who underwent TAVR with carotid compression. The valve technologies included in the study were SAPIEN XT and S3 (Edward Lifesciences, Irvine, California, USA). To control for any potential differences in pathophysiology related to access approach, only patients who underwent a TAVR procedure via the transfemoral access route were included in this study. Patients whose pre-procedure carotid stenosis status had not been measured were not included in the study, nor were patients with bilateral carotid disease. All patients for whom anticoagulation medication was not contraindicated received dual anti-platelet therapy with aspirin and clopidogrel for 6 months after TAVR. Intravenous heparin was administered during the procedure to obtain an activated clotting time goal of $>300 \mathrm{~s}$. Taking into account contraindications, there was no significant difference between groups with regard to the administration of anticoagulation medication at discharge (98.4\% for Group I vs. $97.5 \%$ for Group II, $P$ $=0.95$ ).

At the University of Utah Hospital, it is standard practice to perform carotid compression on patients receiving SAPIEN valves; however, carotid compression is not used at the other two centers, therefore data from these centers served as a control. Carotid compression is defined as bilateral external compression of the carotid arteries and is performed coincident with rapid pacing. In this study, carotid compression was initiated $2 \mathrm{~s}$ before rapid pacing and released $3 \mathrm{~s}$ after rapid pacing was discontinued, with the average duration of carotid compression lasting 30-45 s. Carotid compression was completed manually with enough pressure to feel the carotid compressed and was completed by the assisting physician. Stroke and TIA were defined according to Valve Academic Research Consortium (VARC) criteria [19]. TIA was defined as a new focal or global neurological deficit with symptom resolution within 24 hours of onset in the 
Table 1. Non-adjusted baseline characteristics.

\begin{tabular}{|c|c|c|c|}
\hline Variable & $\begin{array}{l}\text { No Carotid } \\
\text { compression } \\
n=188\end{array}$ & $\begin{array}{l}\text { Carotid } \\
\text { compression } \\
n=118\end{array}$ & p value \\
\hline Age & $81.9 \pm 8.1$ & $78.8 \pm 7.3$ & $<0.001$ \\
\hline Females & $48.5 \%$ & $39.4 \%$ & 0.05 \\
\hline Caucasian race & $93.1 \%$ & $97.1 \%$ & 0.06 \\
\hline Diabetes & $43.5 \%$ & $40.6 \%$ & 0.52 \\
\hline Hypertension & $96.1 \%$ & $89.7 \%$ & 0.003 \\
\hline Atrial fibrillation & $48.9 \%$ & $36.6 \%$ & 0.008 \\
\hline $\begin{array}{l}\text { Prior Stroke or } \\
\text { TIA }\end{array}$ & $23.8 \%$ & $18.9 \%$ & 0.20 \\
\hline Prior Ml & $36.8 \%$ & $23.4 \%$ & 0.002 \\
\hline $\begin{array}{l}\text { Prior CAD } \\
\text { (CABG or } \mathrm{PCl})\end{array}$ & $55.1 \%$ & $49.4 \%$ & 0.22 \\
\hline $\begin{array}{l}\text { Current } \\
\text { Tobacco Use }\end{array}$ & $6.9 \%$ & $7.4 \%$ & 0.83 \\
\hline COPD & $34.4 \%$ & $27.4 \%$ & 0.11 \\
\hline Prior PVD & $40.4 \%$ & $30.3 \%$ & 0.02 \\
\hline $\begin{array}{l}\text { Carotid Stenosis } \\
(\mathrm{L} / \mathrm{R})\end{array}$ & $22.7 \%$ & $17.1 \%$ & 0.14 \\
\hline $\begin{array}{l}\text { Baseline LVEF } \\
(>30 \%)\end{array}$ & $93.3 \%$ & $96.6 \%$ & 0.13 \\
\hline $\mathrm{BMI}$ & $28.5 \pm 6.9$ & $28.3 \pm 6.2$ & 0.80 \\
\hline STS Score & $8.47 \pm 4.4$ & $9.24 \pm 5.9$ & 0.12 \\
\hline
\end{tabular}

absence of other possible causes and was confirmed by a neurologist. Stroke was defined as rapid onset of a focal or global neurological deficit lasting $\geq 24$ hours (or $<24$ hours if therapeutic interventions were performed) in the absence of other identifiable nonstroke causes and was confirmed by a neurologist. In keeping with the VARC recommendation, a disabling stroke (also known as a "major stroke") was defined as a stroke with degree of disability $\geq 2$ on the modified Rankin scale. Post-procedure neurologic events ("post-procedure cardiovascular accidents (CVA)") were defined as any TIA or stroke documented within 72 hours of TAVR, whereas a late neurologic event ("late CVA") was defined as any TIA or stroke documented between 72 hours of TAVR (or at discharge) and 30 days after TAVR. In this study, high-volume TAVR is defined as $>100$ TAVR cases annually, with all three centers meeting this definition. This study was
Table 2. Non-adjusted procedure characteristics.

\begin{tabular}{|c|c|c|c|}
\hline Variable & $\begin{array}{l}\text { No Carotid } \\
\text { Compression }\end{array}$ & Carotid Compression & p value \\
\hline $\begin{array}{l}\text { LOS Post-Proce- } \\
\text { dure (days) }\end{array}$ & $6.8 \pm 5.6$ & $6.3 \pm 4.8$ & 0.28 \\
\hline $\begin{array}{l}\text { Prior aortic } \\
\text { valve procedure }\end{array}$ & $18.3 \%$ & $8.0 \%$ & 0.002 \\
\hline $\begin{array}{l}\text { Pre-procedure } \\
\text { anticoagulants }\end{array}$ & $43.8 \%$ & $28.0 \%$ & $<0.001$ \\
\hline $\begin{array}{l}\text { Access Site } \\
\cdot \text { TF } \\
\cdot \text { TA + Other }\end{array}$ & $\begin{array}{l}58.7 \% \\
41.3 \%\end{array}$ & $\begin{array}{l}70.3 \% \\
29.7 \%\end{array}$ & 0.01 \\
\hline $\begin{array}{l}\text { Status } \\
\text { - Elective } \\
\text { - Urgent/ } \\
\text { Emergency }\end{array}$ & $\begin{array}{l}85.0 \% \\
15.0 \%\end{array}$ & $\begin{array}{l}92.6 \% \\
7.4 \%\end{array}$ & 0.01 \\
\hline $\begin{array}{l}\text { NYHA Class } \\
\text { - Class I } \\
\text { - Class II } \\
\text { - Class III } \\
\text { - Class IV }\end{array}$ & $\begin{array}{l}2.0 \% \\
6.0 \% \\
46.0 \% \\
46.0 \%\end{array}$ & $\begin{array}{l}0 \% \\
5.7 \% \\
81.7 \% \\
12.6 \%\end{array}$ & $<0.001$ \\
\hline Valve-in-valve & $6.9 \%$ & $5.7 \%$ & 0.60 \\
\hline Annulus size & $22.4 \pm 2.3$ & $23.4 \pm 2.7$ & $<0.001$ \\
\hline $\begin{array}{l}\text { Procedure Time } \\
\text { (minutes) }\end{array}$ & $141.2 \pm 63.2$ & $116.5 \pm 63.2$ & $<0.001$ \\
\hline ICU Hours & $54.5 \pm 91.8$ & $72.7 \pm 90.7$ & 0.03 \\
\hline
\end{tabular}

approved by the institutional review boards at all three centers.

\section{Statistical Analysis}

Baseline Comparison of Treatment Groups. Continuous variables are presented as mean \pm standard deviation (SD) or percentage based on their distribution. In the overall sample, continuous and categorical variables were compared between groups using Student's $t$-tests and Chi-square tests, respectively. Differences were considered statistically significant if $P<0.05$

Development of Propensity Score. One difficulty in using observational data is that there may be different distributions of confounding variables between treatment and control groups. Propensity score analysis with inverse probability weighting (IPW) is a method that can help address imbalances between treat- 
Risk Ratios for Major Stroke/TIA Post-Procedure to 72 Hours

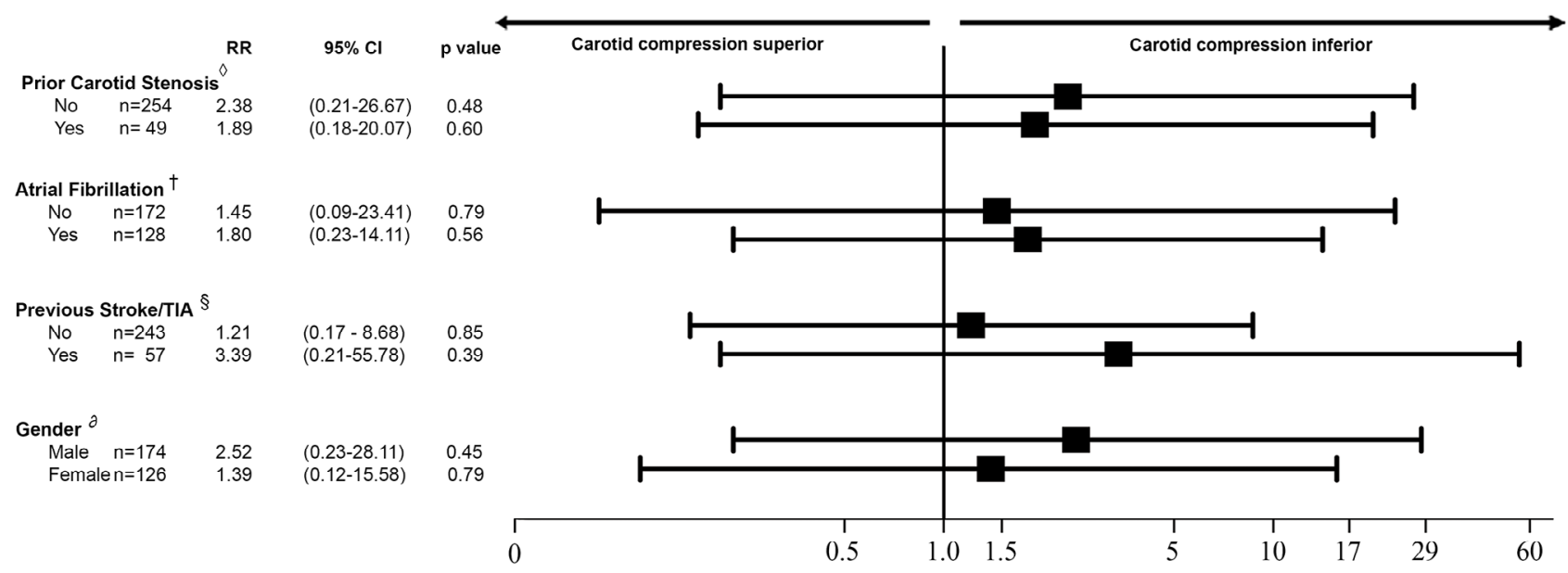

Figure 1. Effects of carotid compression major stroke/TIA post-procedure to 72 hours in subgroups. Carotid compression was shown to be neither superior nor inferior to no carotid compression with regard to combined risk of major stroke or TIA between procedure and 72 hours in subgroups known to have higher risk for stroke or TIA. Due to the low number of overall stroke and TIA events in the population studied, analysis could only be performed on the above subgroups.

$\checkmark$ Interaction between prior carotid stenosis and carotid compression. $p=0.34$ + Interaction between atrial fibrillation and carotid compression. $p=0.24$

$\S$ Interaction between previous stroke/TIA and carotid compression. $p=0.38$

$\partial$ Interaction between gender and carotid compression. $p=0.85$

ment and control groups when there is a likelihood of potential selection bias due to nonrandom treatment assignment [20]. As matching is not employed with IPW, this method has the benefit of balancing propensity scores without needing to drop any patients for whom suitable matches cannot be found. A propensity score is the conditional probability of receiving a treatment based on observed potential confounding variables. In this study, the propensity score represents a patient's probability of receiving carotid compression or no carotid compression as a function of baseline and procedural characteristics.

Several covariates that have been linked to the risk of stroke post-TAVR were included in the propensity score model, including new onset of atrial fibrillation, gender, and chronic kidney disease [21]. An initial propensity score model was estimated using 27 variables described in Tables 1 and 2. To estimate propensity scores, logistic regression models were used in which treatment status was regressed on the baseline characteristics listed in Tables 1 and 2. Continuous baseline variables were linearly related to the log-odds of receipt of carotid compression in the initial specifi- cation of the propensity score model. Prior research on variable selection for propensity scores suggests that it is desirable to include variables that affect the outcome [22], therefore variables that appeared to impact the outcome were included in the initial propensity score model. Due to our smaller sample size, we chose to remove irrelevant covariates to avoid introducing "noise" into the treatment effect estimates [22]. Propensity scores were modeled as a function of age, pre-procedure hypertension, pre-procedure atrial fibrillation, previous aortic valve procedure, NYHA classification, anticoagulation medication within 24 hours before the TAVR procedure, TAVR procedure time, and pre-procedure aortic valve annulus size. After a propensity score was calculated for each subject, we evaluated the overlap in the range of propensity scores between groups as well as the balance (i.e., distributions) across groups. Although there is no standard guideline for how much imbalance is acceptable, standardized differences for covariates ranging up to 0.25 are acceptable [23]. Balance was achieved with our covariates across groups (Table 3 ). 
Table 3. Covariate balance across control and treatment groups after weighting on the propensity score.

\begin{tabular}{|c|c|c|c|}
\hline Covariate & $\begin{array}{l}\text { No Carotid } \\
\text { Compression } \\
\text { (standard- } \\
\text { ized mean) }\end{array}$ & $\begin{array}{l}\text { Carotid } \\
\text { Compression } \\
\text { (standardized } \\
\text { mean) }\end{array}$ & $\begin{array}{l}\text { Standardized } \\
\text { Difference } \\
(\%)\end{array}$ \\
\hline Age & 80.96 & 80.29 & 8.5 \\
\hline Female & 0.45 & 0.45 & 0.0 \\
\hline Hypertension & 0.94 & 0.93 & 3.8 \\
\hline $\begin{array}{l}\text { Atrial fibrillation } \\
\text { - pre-procedure }\end{array}$ & 0.44 & 0.48 & -9.6 \\
\hline COPD & 0.31 & 0.29 & 5.3 \\
\hline $\begin{array}{l}\text { Baseline EF } \\
(<30 \%)\end{array}$ & 0.05 & 0.03 & 11.4 \\
\hline BMI & 28.74 & 28.19 & 7.9 \\
\hline $\begin{array}{l}\text { Chronic Kidney } \\
\text { Disease }\end{array}$ & 0.54 & 0.53 & 2.5 \\
\hline $\begin{array}{l}\text { Prior aortic } \\
\text { valve procedure }\end{array}$ & 0.14 & 0.08 & 19.9 \\
\hline $\begin{array}{l}\text { Anticoagulants } \\
\text { pre-procedure }\end{array}$ & 0.40 & 0.46 & -13.3 \\
\hline Procedure time & 131.27 & 133.77 & -4.0 \\
\hline Annulus size & 22.80 & 22.65 & 5.8 \\
\hline $\begin{array}{l}\text { Atrial fibrillation } \\
\text { - new, post-pro- } \\
\text { cedure }\end{array}$ & 0.02 & 0.00 & 10.0 \\
\hline
\end{tabular}

Data Analysis. Adjusted risk ratios for post-procedure and late stroke were estimated with $95 \%$ confidence intervals $(\mathrm{Cls})$ using a Poisson regression model. All statistical analyses were performed with STATA software (Stata Statistical Software: Release 14, StataCorp, College Station, Texas, USA).

\section{Results}

\section{Patient Demographic and Procedural Characteristics}

A total of 306 TAVR patients from three high-volume TAVR centers were included in the study. Group I consisted of 188 patients, and Group II consisted of 118 patients. There were 118 patients (38.6\%) from the University of Utah, 142 (46.4\%) from the University of Washington, and 46 (15.0\%) from Banner Health Center. Patient demographic characteristics are shown in Table 1. Mean age was $82.5 \pm 8.2$ years in Group I and $78.5 \pm 7.6$ years in Group II. There were more males in both Group I and II (54.3\% and 63.6\%, respectively). Procedural characteristics are shown in Table 2. The average length of stay was $5.8 \pm 4.6$ days in Group I and $5.1 \pm 3.8$ days in Group II.

\section{Unadjusted Results}

Before propensity adjustment, post-procedure CVAs were observed in $1.6 \%$ of patients in Group I and $2.5 \%$ of patients in Group II, with a risk ratio (RR) of $1.59(95 \% \mathrm{Cl}, 0.33-7.78, P=0.57)$. Late CVA rates were $2.7 \%$ in Group I and $2.5 \%$ in Group II, with a RR of $0.96(\mathrm{Cl} 95 \%, 0.23-3.94, P=0.95)$.

\section{Adjusted Results}

After propensity adjustment, post-procedure CVAs were observed in $1.1 \%$ of patients in Group I and $1.9 \%$ of patients in Group II, with a RR of 1.77 (95\% $\mathrm{Cl}, 0.34-9.39, P=0.50)$. Late CVA rates were $2.3 \%$ for Group I and 1.6\% for Group II, with a RR of 0.72 (95\% $\mathrm{Cl}, 0.16-3.18, P=0.67)$.

\section{Subgroup Analysis}

We evaluated the association between specific clinical characteristics and carotid compression with regard to disabling stroke and TIA risk after the procedure. Due to the small number of events, subgroup analysis could be completed only for the following baseline characteristics: carotid stenosis, atrial fibrillation, previous stroke or TIA, and gender. There were no changes in risk of disabling stroke at discharge among analyzed subgroups (Figure 1).

\section{Discussion}

We found that patients who received or did not receive carotid compression during TAVR exhibited no significant difference in risk of disabling stroke after the procedure. While the data do not show any benefit in the use of carotid compression, they also do not show evidence of harm associated with carotid compression. It is possible that carotid compression may limit microemboli. The clinical significance, of any, of microemboli detected by transcranial Doppler that do not manifest in overt TIA or stroke is still unknown [24].

Stroke Prevention with Carotid Compression During TAVR 
TAVR is the gold standard therapy for inoperable patients with symptomatic severe AS [1, 3]. Recently, TAVR has been indicated for intermediate risk patients [2]. The use of TAVR in a wider range of patient populations has paralleled improvements in valve technology aimed at reducing the risk of complications such as vascular injury and stroke [25]. The 30day stroke rate in the PARTNER 1A trial was significantly higher among patients in the TAVR group than among patients in the medical therapy group $(6.7 \%$ vs. $1.7 \%, P=0.04)$ or the SAVR group (5.5\% vs. $2.4 \%, P$ $=0.04)[1,3]$. In the PARTNER 1A trial, $38 \%$ of strokes occurred within 2 days and $58 \%$ within 30 days in patients undergoing TAVR. Risk factors for stroke in the PARTNER 1A trial were use of TAVR and small native aortic valve area [9]. The risk of post-TAVR stroke in other studies ranged between $1.7 \%$ and $8.4 \%[7,26$, 27]. This wide difference in reported stroke rate in the literature is likely secondary to inconsistencies in the definitions of acute neurological events. However, a systematic review of the literature shows that stroke rates have declined over the last decade as delivery systems have become smaller, the systematic use of heparin has increased, and technical experience has improved $[7,25,28]$.

The mechanism of stroke in TAVR is multifactorial but largely thought to be secondary to embolization. This may be in part due to liberation of calcific material during valve implantation. Other factors contributing to the development of stroke are manipulation of wires and catheters at the level of the aortic arch and root during the transfemoral approach and manipulation of the apex during the transapical approach [29]. Although studies have implicated embolization during the procedure as a potential cause of stroke [30], and bilateral carotid disease is a predictive factor for post-procedure stroke [12], the main source of emboli remains unclear. Clinically silent emboli to the brain have been detected in the majority of patients after TAVR [14, 16, 24, 31]. Several studies have used transcranial Doppler to identify high-intensity transient signal (HITS) as a surrogate for microembolization. Procedural HITS was identified in all patients, with the highest HITS detected for the transfemoral approach with the self-expanding Medtronic Core Valve, mainly during implantation $[14,29,30]$. In our study, neuroimaging testing was not used to deter-

Journal of Structural Heart Disease, February 2018 mine the impact of carotid compression on the burden of asymptomatic microembolization. The valve design did not seem to alter the risk of stroke after TAVR. The FRANCE 2 Registry showed no statistically significant difference between the balloon-expanding Edwards SAPIEN valve and the self-expanding Core Valve in terms of stroke outcome [32].

The use of carotid compression to influence cerebral embolization during cardiac procedures is controversial, with little published data in support of this practice. Asahi et al. [33] used magnetic resonance angiography to examine the effects of unilateral carotid compression on cerebral flow patterns in two human volunteers. They demonstrated clear changes in perfusion patterns and flow directions within the cerebral vasculature that recovered with decompression. Hillebrand et al. [18] studied 20 patients undergoing a variety of open cardiac surgeries and performed transcranial Doppler of the middle cerebral artery. They found that digital carotid compression reduced the incidence of cerebral emboli during aortic cannulation and declamping. The lack of efficacy of carotid compression during TAVR in the present study may be explained by the fact that microemboli occur during every step of TAVR, not just during valve deployment, as shown by TCD monitoring [14], although there is clearly a peak during valve positioning and deployment. In addition, there is no consensus on the timing and level of pressure that should be applied to potentially prevent stroke.

Another approach to preventing stroke after TAVR is the use of embolic protection devices. There is evidence to suggest that the use of embolic protection devices is associated with a smaller volume of silent ischemic lesions and a smaller total volume of lesions, but there is no related decrease in clinically relevant strokes [34] and no significant change in neurocognitive function $[15,16,24]$.

Although the specific causes of ischemic stroke in TAVR patients have yet to be fully identified, several factors may increase a patient's risk of post-procedure stroke, including chronic kidney disease, new onset atrial fibrillation [11, 21], post-deployment balloon dilation, and pure aortic stenosis without regurgitation [26]. Because stroke increases a patient's risk for mortality [35] and can negatively impact quality of life for patients and their families [36], and there is evidence 
that early treatment of ischemic stroke results in better patient outcomes [37], it might be worthwhile to consider post-procedure treatment plans specifically designed for patients determined to be at a higher risk of post-procedure stroke.

Some limitations of this study must be considered. This study is a retrospective analysis of a relatively small number of patients. Although this is a multi-center study, carotid compression was performed at only one of the three study sites, and the overall number of outcome events was small. The study did not involve neuroimaging testing to verify the impact of carotid compression on the burden of clinically silent emboli. Larger cohort trials are needed to validate the results of this study.

In conclusion, stroke prevention by means of the non-invasive technique of using carotid compression during TAVR may not impact the incidence of TIA or disabling stroke after TAVR. Further research into the relationship between carotid disease and post-procedure stroke in TAVR patients is warranted.

\section{Acknowledgements}

This investigation was supported by the University of Utah Study Design and Biostatistics Center, with funding in part from the National Center for Research Resources and the National Center for Advancing Translational Sciences, National Institutes of Health, through Grant 8UL1TR000105 (formerly UL1RR025764).

\section{Conflict of Interest}

The authors have no conflict of interest relevant to this publication.

\section{Comment on this Article or Ask a Question}

\section{References}

1. Leon MB, Smith CR, Mack M, Miller DC, Moses JW, Svensson LG, et al. Transcatheter aortic-valve implantation for aortic stenosis in patients who cannot undergo surgery. N Engl J Med. 2010;363:1597-1607. DOI: 10.1056/NEJMoa1008232

2. Leon MB, Smith CR, Mack MJ, Makkar RR, Svensson LG, Kodali SK, et al. Transcatheter or surgical aortic-valve replacement in intermediate-risk patients. N Engl J Med. 2016;374:1609-1620. DOI: 10.1056/NEJMoa1514616

3. Smith $C R$, Leon $M B$, Mack MJ, Miller DC, Moses JW, Svensson LG, et al. Transcatheter versus surgical aortic-valve replacement in high-risk patients. N Engl J Med. 2011;364:2187-2198. DOI: 10.1056/NEJMoa1103510

4. Stortecky S, Windecker S. Stroke: An infrequent but devastating complication in cardiovascular interventions. Circulation. 2012;126:2921-2924. DOI: 10.1161/CIRCULATIONAHA.112.149492

5. Mack MJ, Leon MB, Smith CR, Miller DC, Moses JW, Tuzcu EM, et al. 5-year outcomes of transcatheter aortic valve replacement or surgical aortic valve replacement for high surgical risk patients with aortic stenosis (PARTNER 1): a randomised controlled trial. Lancet. 2015;385:2477-2484. DOI: 10.1016/ S0140-6736(15)60308-7

6. Gilard $M$, Eltchaninoff $H$, lung $B$, DonzeauGouge P, Chevreul K, Fajadet J, et al. Reg- istry of transcatheter aortic-valve implantation in high-risk patients. N Engl J Med. 2012;366:1705-1715. DOI: 10.1056/NEJMoa1114705

7. Di Mario $\mathrm{C}$, Eltchaninoff $\mathrm{H}$, Moat $\mathrm{N}$, Goicolea J, Ussia GP, Kala P, et al. The 201112 pilot European Sentinel Registry of Transcatheter Aortic Valve Implantation: in-hospital results in 4,571 patients. Eurolntervention. 2013;8:1362-1371. DOI: 10.4244/EIJV8I12A209

8. Holmes DR Jr, Brennan JM, Rumsfeld JS, Dai D, O'Brien SM, Vemulapalli $S$, et al. Clinical outcomes at 1 year following transcatheter aortic valve replacement. JAMA. 2015;313:1019-1028. DOI: 10.1001/ jama.2015.1474

9. Miller DC, Blackstone EH, Mack MJ, Svensson LG, Kodali SK, Kapadia S, et al. Transcatheter (TAVR) versus surgical (AVR) aortic valve replacement: occurrence, hazard, risk factors, and consequences of neurologic events in the PARTNER trial. J Thorac Cardiovasc Surg. 2012;143:832-843.e13. DOI: 10.1016/j.jtcvs.2012.01.055

10. Tay EL, Gurvitch R, Wijesinghe N, Wood D, Cheung A, Ye J, et al. A high-risk period for cerebrovascular events exists after transcatheter aortic valve implantation. JACC Cardiovasc Interv. 2011;4:1290-1297. DOI: 10.1016/j.jcin.2011.08.012

11. Nombela-Franco L, Webb JG, de Jaegere PP, Toggweiler S, Nuis RJ, Dager AE, et al.
Timing, predictive factors, and prognostic value of cerebrovascular events in a large cohort of patients undergoing transcatheter aortic valve implantation. Circulation. 2012;126:3041-3053. DOI: 10.1161/CIRCULATIONAHA.112.110981

12. Thirumala $P$, Muluk $S$, Udesh R, Mehta $A$, Schindler J, Mulukutla S, et al. Carotid artery disease and periprocedural stroke risk after transcatheter aortic valve implantation. Ann Card Anaesth. 2017;20:145-151. DOI: 10.4103/aca.ACA_13_17

13. Ghanem A, Naderi AS, Frerker C, Nickenig G, Kuck KH. Mechanisms and prevention of TAVI-related cerebrovascular events. Curr Pharm Des. 2016;22:1879-1887. DOI: 10.21 74/1381612822666151217122610

14. Kahlert P, Al-Rashid F, Dottger P, Mori K, Plicht B, Wendt D, et al. Cerebral embolization during transcatheter aortic valve implantation: a transcranial Doppler study. Circulation. 2012;126:1245-1255. DOI: 10.1161/CIRCULATIONAHA.112.092544

15. Kahlert $P$, Al-Rashid F, Plicht B, Hildebrandt $H$, Patsalis $P$, Chilali $K E$, et al. Incidence, predictors, origin and prevention of early and late neurological events after transcatheter aortic valve implantation (TAVI): A comprehensive review of current data. J Thromb Thrombolysis. 2013;35:436-449. DOI: 10.1007/s11239-012-0863-y

16. Kahlert P, Knipp SC, Schlamann M, Thielmann M, Al-Rashid F, Weber M, et al., Silent 
and apparent cerebral ischemia after percutaneous transfemoral aortic valve implantation: a diffusion-weighted magnetic resonance imaging study. Circulation. 2010;121:870-878. DOI: 10.1161/CIRCULATIONAHA.109.855866

17. Van Mieghem NM, Schipper ME, Ladich $E_{,}$ Fagiri $E$, van der Boon R, Randjgari $A$, et al. Histopathology of embolic debris captured during transcatheter aortic valve replacement. Circulation. 2013;127:21942201. DOI: 10.1161/CIRCULATIONAHA.112.001091

18. Hillebrand J, Rouhollahpour A, Zierer A, Moritz A, Martens S. Digital carotid compression: A simple method to reduce solid cerebral emboli during cardiac surgery. J Cardiothorac Vasc Anesth. 2016;30:304308. DOI: 10.1053/j.jvca.2015.11.017

19. Kappetein AP, Head SJ, Genereux P, Piazza N, van Mieghem NM, Blackstone EH, et al. Updated standardized endpoint definitions for transcatheter aortic valve implantation: The valve academic research consortium-2 consensus document. J Am Coll Cardiol. 2012;60:1438-1454. DOI: 10.1016/j.jacc.2012.09.001

20. Garrido MM, Kelley AS, Paris J, Roza K, Meier DE, Morrison RS, et al. Methods for Constructing and Assessing Propensity Scores. Health Serv Res. 2014;49:1701-1720. DOI: 10.1111/1475-6773.12182

21. Auffret V, Regueiro A, Del Trigo $M, A b$ dul-Jawad Altisent $\mathrm{O}$, Campelo-Parada $F$, Chiche $O$, et al. Predictors of early cerebrovascular events in patients with aortic stenosis undergoing transcatheter aortic valve replacement. J Am Coll Cardiol. 2016;68:673-684. DOI: 10.1016/j. jacc.2016.05.065

22. Brookhart MA, Schneeweiss $S$, Rothman KJ, Glynn RJ, Avorn J, Stürmer T. Variable selection for propensity score models. Am J Epidemiol. 2006;163:1149-1156. DOI: 10.1093/aje/kwj149

23. Stuart EA, BK Lee, Leacy FP. Prognostic score-based balance measures can be a useful diagnostic for propensity score methods in comparative effectiveness research. J Clin Epidemiol. 2013;66:S84-S90. e1. DOI: 10.1016/j.jclinepi.2013.01.013

24. Ghanem A, Kocurek J, Sinning JM, Wagner $M$, Becker BV, Vogel M, et al. Cognitive trajectory after transcatheter aortic valve im- plantation. Circ Cardiovas Interv. 2013. DOI: 10.1161/CIRCINTERVENTIONS.112.000429

25. Athappan G, Gajulapalli RD, Sengodan P, Bhardwaj A, Ellis SG, Svensson L, et al. Influence of transcatheter aortic valve replacement strategy and valve design on stroke after transcatheter aortic valve replacement. J Am Coll Cardiol. 2014;63:21012110. DOI: 10.1016/j.jacc.2014.02.540

26. Kapadia S, Agarwal S, Miller DC, Webb JG, Mack M, Ellis S, et al. Insights into timing, risk factors, and outcomes of stroke and transient ischemic attack after transcatheter aortic valve replacement in the PARTNER trial (Placement of Aortic Transcatheter Valves). Circ Cardiovas Interv. 2016;9:e002981. DOI: 10.1161/CIRCINTERVENTIONS.115.002981

27. Kleiman NS, Maini BJ, Reardon MJ, Conte J, Katz S, Rajagopal V, et al. Neurological events following transcatheter aortic valve replacement and their predictors: A report from the CoreValve trials. Circ Cardiovasc Interv. 2016;9:e003551. DOI: 10.1161/CIRCINTERVENTIONS.115.003551

28. Spaziano $M$, Francese DP, Leon $M B$, Généreux $P$. Imaging and functional testing to assess clinical and subclinical neurological events after transcatheter or surgical aortic valve replacement. J Am Coll Cardiol. 2014;64:1950-1963. DOI: 10.1016/j. jacc.2014.07.986

29. Szeto WY, Augoustides JG, Desai ND, Moeller P, McGarvey ML, Walsh E, et al. Cerebral embolic exposure during transfemoral and transapical transcatheter aortic valve teplacement. J Card Surg. 201 1;26:348-354. DOI: 10.1111/j.1540-8191.2011.01265.x

30. Erdoes G, Basciani R, Huber C, Stortecky S, Wenaweser $P$, Windecker $S$, et al. Transcranial Doppler-detected cerebral embolic load during transcatheter aortic valve implantation. Eur J Cardiothorac Surg. 2012;41:778784. DOI: $10.1093 /$ ejcts/ezr068

31. Rodés-Cabau J, Kahlert $P$, Neumann FJ, Schymik G, Webb JG, Amarenco P, et al. Feasibility and exploratory efficacy evaluation of the Embrella Embolic Deflector system for the prevention of cerebral emboli in patients undergoing transcatheter aortic valve replacement. JACC CardiovasC Interv. 2014;7:1146-1155. DOI: 10.1016/j. jcin.2014.04.019

32. Bière $L$, Durfort $A$, Fouquet $O$, Hamel JF,
Leprince $P$, Chevreul K, et al. Baseline characteristics and outcomes after transcatheter aortic-valve implantation in patients with or without previous balloon aortic valvuloplasty: Insights from the FRANCE 2 registry. Arch Cardiovas Dis. 2017;110:534542. DOI: $10.1016 /$ j.acvd.2016.12.012

33. Asahi K, Hori M, Hamasaki N, Sato S, Nakanishi $\mathrm{H}$, Kuwatsuru $\mathrm{R}$, et al. Dynamic alteration of regional cerebral blood flow during carotid compression and proof of reversibility. Acta Radiologica Short Reports. 2012;1:arsr.2012.110015. DOI: 10.1258/arsr.2012.110015

34. Bagur R, Solo K, Alghofaili S, Nombela-Franco L, Kwok CS, Hayman S, et al. Cerebral embolic protection devices during transcatheter aortic valve implantation: Systematic review and meta-analysis. Stroke. 2017;48:1306-1315. DOI: 10.1161/ STROKEAHA.116.015915

35. Hedberg M, Boivie P, Engstrom KG. Early and delayed stroke after coronary surgery - an analysis of risk factors and the impact on short- and long-term survival. Eur J Cardiothorac Surg. 2011;40:379-387. DOI: 10.1016/j.ejcts.2010.11.060

36. Caro CC, Mendes PV, Costa JD, Nock LJ, Cruz DM. Independence and cognition post-stroke and its relationship to burden and quality of life of family caregivers. Top Stroke Rehabil. 2017;24:194-199. DOI: 10.1080/10749357.2016.1234224

37. Hacke W, Donnan G, Fieschi C, Kaste M, von Kummer R, Broderick JP, et al. Association of outcome with early stroke treatment: pooled analysis of ATLANTIS, ECASS, and NINDS rt-PA stroke trials. Lancet. 2004;363:768-774. DOI: 10.1016/S01406736(04)15692-4

Cite this article as: Tandar A, Luton $\mathrm{K}$, Saidi A, Lindman BR, Bull D, Glotzbach J, Selzman CH, Patel A, Stoddard G, Dranow E, Welt FG. Stroke Prevention With Carotid Compression in Patients Undergoing Transcatheter Aortic Valve Replacement: a Multi-Center Study. Structural Heart Disease. 2018;4(1):916. DOI: https://doi.org/10.12945/j. jshd.2018.032.17 